\title{
Psychologists' Perspectives on the Psychological Suffering of Refugee Patients in Brazil
}

\author{
Gesa Solveig Duden ${ }^{1,2}$ (D) Sofie de Smet $^{3}$. \\ Lucienne Martins-Borges ${ }^{2,4}$
}

Accepted: 18 March 2021 / Published online: 22 April 2021

(C) The Author(s) 2021

\begin{abstract}
Worldwide there are 79.5 million displaced people, many of which face war, violence, tragic flights and struggles in host countries. Research shows augmented prevalence rates of mental disorders among refugees internationally, but little is known about refugee mental health in Latin American countries. Furthermore, only a few studies have taken into consideration the knowledge of clinical psychologists who treat refugee patients. The present study examines the experiences of 32 psychologists in Brazil regarding their refugee patients' psychological suffering and mental disorders. Semi-structured interviews were conducted in various locations in Brazil and analysed following a consensual qualitative research approach. Four clusters of refugee patients' suffering were synthesised: post-migration stressors, traumatic experiences, flight as life rupture, and the current situation in the country of origin. The most frequently described conditions in patients were anxiety and depression. However, the results also show that the use of
\end{abstract}

$\triangle$ Gesa Solveig Duden

gduden@uni-osnabrueck.de

Sofie de Smet

sofied.desmet@ugent.be

Lucienne Martins-Borges

lucienne.martins-borges@tsc.ulaval.ca

1 Department of Psychology, University of Osnabrück, Neuer Graben, 49074 Osnabrück, Germany

2 Departamento de Psicologia, Universidade Federal de Santa Catarina, Campus Universitário Trindade, Florianópolis, SC CEP: 88040-500, Brazil

3 Parental and Special Education Research Unit, Refugee Trauma Care-Clinical Centre PraxisP, Faculty of Psychology \& Educational Sciences, University of Leuven, Leopold Vanderkelenstraat 32 bus 3764, Louvain 3000, Belgium

4 École de Travail Social et de Criminologie, Faculté des sciences sociales, Université Laval, Avenue des Sciences-Humaines, Quebec G1V 0A6, Canada 
manuals for the classification of mental disorders is contested among psychologists in Brazil. Most psychologists stressed patients' socio-political suffering and saw patients' symptoms as normal reactions to their experiences. There is a need to acknowledge the socio-political suffering of refugees in Brazil and foster their mental health by tackling current post-migration stressors such as discrimination.

Keywords Refugee mental health in Brazil · Qualitative interviews · Psychiatric diagnostic manual · Depression · Anxiety

\section{Introduction}

Mental healthcare for refugee patients ${ }^{1}$ is an issue of international concern and is growing in importance as the number of displaced people worldwide is rising and now exceeds 79.5 million (UNHCR 2020). Refugees are very heterogenous and becoming and being a refugee is not of psychological, but of socio-political nature (Papadopoulos 2007). However, many studies find higher prevalence rates of mental disorders in refugees in comparison to the general population of host countries. For instance, rates of post-traumatic stress disorder (PTSD) have been found to be up to 10 times higher in refugees than in the general population (Fazel, Wheeler and Danesh 2005). Elevated rates of depression and anxiety ${ }^{2}$ have also been described in refugees (Lindert et al. 2009; Turrini et al. 2017). These findings can be explained by the psychological impacts of pre-flight exposure to war, persecution and violence, the displacement experience and post-migration struggles in host countries (Knipscheer and Kleber 2006; Miller and Rasmussen 2010).

Recently, research on refugee mental health has shifted from the concentration on pre-migration trauma towards a focus on post-migration stressors (Davidson, Murray and Schweitzer 2008; Silove, Ventevogel and Rees 2017) and on how these stressors might interplay with and exacerbate previous traumas and suffering (Cleveland, Rousseau and Guzder 2014). Post-migration stressors include experiences of culture shock and cultural bereavement (Bhugra and Becker 2005; Eisenbruch 1991; Oberg 1960), social isolation (Miller and Rasmussen 2010), discrimination (Beiser and Hou 2016), prolonged detention, tedious asylum application procedures, insecure residency status (Comtesse and Rosner 2019;

\footnotetext{
${ }^{1}$ Displaced people include various groups such as refugees who have been officially recognised as such, asylum seekers who are still waiting for a decision on their refugee status and people with humanitarian visas who do not fall officially under the UN definition of a "refugee", as for instance many Haitians in Brazil. Nevertheless, the present article will refer to all of these people as refugees. Firstly, we hope this facilitates easier reading. Secondly, grouping these very heterogenous people together is based on the assumption that displaced people find themselves in a comparable predicament that is distinct from that of the general population.

2 Throughout the article, the denomination of terms of mental illnesses (e.g. "depressive disorder") is in accordance with the respective reference from which the term was taken. Furthermore, the expression "psychological suffering" is used to allow for the inclusion of a range of experiences and mental states that are considered troubling, confusing or not perceived to be healthy by the people concerned. This expression was chosen to capture a wider scope of problems than the designation "mental disorder" would characterise.
} 
Davidson, Murray and Schweitzer 2008), financial troubles (Bogic et al. 2012), limited access to services and unemployment (Silove, Ventevogel and Rees 2017).

The post-migration stressors are primarily shaped by the juristic, structural, cultural and societal conditions of the host countries which vary considerably from country to country (Davidson, Murray and Schweitzer 2008). This makes the experiences and suffering of refugees unique in each context. Furthermore, societal conditions, together with traditions in psychological sciences, influence what is considered mentally healthy or pathological (Kirmayer et al. 2015). Meanwhile, most studies investigating the mental health of refugees in host countries stem from the Global North and high-income countries. This prevalent selective geographical bias that is present in psychological research in general, leads to mental health concerns being defined by high-income countries (Kirmayer and Pedersen 2014). Some studies have looked at refugee mental health in middle- or low-income countries such as Bosnia, Uganda and Sudan (see Reed et al. 2012). In Latin American countries until 2009 few studies concerning refugees had been conducted (de Moraes Weintraub 2012; da Teixeira, Lotufo Neto and Skokauskas 2013). However, recently, with the increase in migrants and refugees, particularly from Haiti and Venezuela, more studies have focused on refugees in Latin America, such as on Colombian refugees in Ecuador (Carrasco García 2010) or in Chile (Liberona Concha and López San Francisco 2018), on Palestinian refugees in Chile (Bijit Abde 2012), on Haitian immigrants (Barros and Martins-Borges 2018) and on Syrian refugees in Brazil (Jibrin 2017; Lodetti 2018). However, there remains a need to study concepts of pathology, in particular related to the mental health of refugees, in a greater variety of cultures and contexts (Duden \& Martins-Borges 2021) and to insert such studies and their findings into an (Anglophone-dominated) global research world, in order to call international attention to these studies and findings from diverse contexts. Following the suggestion of an inside-out model that prioritises the perspectives of those underrepresented in research (Gergen, Josselson and Freeman 2015; Hall, Yip and Zárate 2016; Syed et al. 2018), the present study aimed to look at the perspectives of psychologists who treat refugees in Brazil.

In Brazil, by June 2020, the total number of recognised refugees exceeded 43,000 of which about 38,000 are Venezuelans (Agência Brasil 2020; CONARE 2020). About 80,000 new applications were submitted in 2018 alone (CONARE 2020). This represents a considerable increase in asylum applications in Brazil, inter alia related to the earthquake in Haiti in 2010 and the humanitarian crisis in Venezuela from 2016 onwards. Brazilian jurisdiction relies on a comparably broad definition of "refugee" and also allows the possibility of humanitarian visa (Bógus and Rodrigues 2011; Patarra and Fernandes 2011). In November 2017, the Brazilian state approved the "nova lei de migração" - a new law for migrants, that aims to simplify administrative procedures for immigrants in Brazil. It shifts from a perspective of migrants as risks for national security to a human rights perspective, an emphasis on the guarantee of rights and non-discrimination of migrants (Assis 2018). Among other things, the new law facilitates the passage of by-laws for the concession of humanitarian visa (de Oliveira 2017). Meanwhile, the new law did not pass without opposition. For instance, according to Assis (2018:619), the veto against the use of the term "migrant" in the law (the new law includes only the 
definitions of "immigrant", "emigrant", "border resident", "visitor" and "stateless person") expresses the persistence of aiming to place migrants closer to the idea of strangers and foreigners, instead of fostering a perception of migrants as mobile subjects in the contemporary world, which was what the commission originally set out to establish. Still, there are various notable aspects in the Brazilian jurisdiction for migrants, such as that asylum seekers are granted a work permit directly after applying for asylum, have the same rights to access education, training and healthcare as Brazilians (Assis 2018) and that there is no deportation in Brazil in general (Jubilut 2006; Leão 2011).

The present study aimed to investigate the experiences of psychologists regarding their refugee patients' psychological suffering. We decided to interview professionals as experts due to our assumption that psychologists who encounter refugees in their daily practise might have special insight into the mental health and suffering of their patients (Meuser and Nagel 2009). Investigating their experiences and knowledge might be a valuable first step for understanding refugee patients' situation in Brazil and develop appropriate mental healthcare services. We focused on professionals in Brazil for two main reasons: Firstly, even though there has been a recent increase in studies investigating various aspects of refuge in Brazil (Duden \& Martins-Borges 2021; Barros and Martins-Borges 2018), there is still little information concerning their mental health across several Brazilian states (Braga Bezerra, Martins-Borges and Cunha Pereira 2019; de Moraes Weintraub 2012; da Teixeira, Lotufo Neto and Skokauskas 2013), and even more so, a lack of international attention to this specific field of research. Secondly, gaining the perspectives of experts from a country from the Global South might provide new insights for the discussion on the categorisation of mental disorders (Drodžek 2007; Kirmayer 2001; Summerfield 1999, 2008). Our research design addressed participants' perspectives as culturally mediated phenomena located in the Brazilian context, with the aim to understand "explanatory models" of practitioners (Kleinman 1980). This concept from medical anthropology stresses the importance of causal attributions and ethnophysiological theories on illness experience, but also on treatment response (Kirmayer and Sartorius 2007; Watters 2001). In other words, how psychologists in Brazil think about the suffering of their refugee patients will influence how they attend to the needs of those patients within the Brazilian context.

Specifically, we formulated the following research questions:

How do psychologists who work with refugees in Brazil experience the psychological suffering of their patients?

(a) How do they describe the suffering?

(b) Which mental health disorders and symptoms do they perceive to be most common among their refugee patients? 


\section{Method}

\section{Study Design}

This article forms part of a larger study investigating Brazilian approaches to the mental healthcare of refugees. The focus of the present investigation was how psychologists experience the psychological suffering of their refugee patients. In order to allow for an in-depth analysis of psychologists' perspectives located in the Brazilian socio-political and cultural context, the research project used qualitative procedures of inquiry resting on a constructivist ontology and a subjectivist epistemology. The study consisted of semi-structured interviews which were analysed adopting a consensual qualitative research (CQR; Hill et al. 2005) approach.

\section{Participants and Procedures}

Gatekeepers and contacts to local NGOs were used for recruitment, as well as subsequent snowball sampling. The Ethics Committee of the University of Osnabrück gave ethical approval for the study and informed written consent was obtained from all participants. A semi-structured interview guideline was developed with the objective of encouraging participants to speak about their perspectives on their refugee patients' suffering. It included questions on common characteristics of participants' patients, such as patients' country of origin $(\mathrm{CoO})$, questions on patients' psychological suffering, symptoms and mental health disorders as well as on psychologists' use of diagnostic manuals and categorical classification of mental disorders (MDC). The latter was incorporated to allow for a contextualisation of the findings on frequent disorders, as we assumed that usage of MDC, such as for instance the DSM-5, would influence the way psychologists spoke about patients' suffering. The guideline was pilot tested with Brazilian psychologists to ensure the unambiguity of questions. Between November 2018 and May 2019, semi-structured interviews were conducted with participants $(N=32)$ who held a university degree in psychology and had been working with refugee patients for at least 6 months (Table 1). $44 \%$ of the psychologists were of psychoanalytic orientation, reflecting the often-reported predominance of this approach among general clinical psychologists in Brazil (González 2018; Yamamoto 2012). Eight participants worked with Ethnopsychiatry which is an encounter and complementarism of psychoanalysis and anthropology (Martins-Borges et al. 2019; Nathan 2001). These participants had also taken part in courses of "cultural psychology" during their academic studies and trained in university clinics to attend refugee patients psychologically. None of the other participants had received any specific training to work with survivors of trauma, refugees or to work transculturally, but six of the participants had a migrational background. Most of the participants did not exclusively attend refugee patients, but also worked with other immigrants and Brazilians.

Interviews lasted between $40 \mathrm{~min}$ and $2 \mathrm{~h}$. They were conducted in Portuguese, either face-to-face at participants' workplaces $(n=19)$ or via skype $(n=13)$, audio 
Table 1 Participants' characteristics

\begin{tabular}{|c|c|c|}
\hline Characteristic $(N=32)$ & $N(\%)$ or $M(\mathrm{SD})$ & Range \\
\hline Age (years) & $34.76(10.73)$ & $23-61$ \\
\hline Experience working with refugees (years) & $3.88(3.9)$ & $1-20$ \\
\hline \multicolumn{3}{|l|}{ Region of work } \\
\hline North & $6(19)$ & \\
\hline Southeast & $7(22)$ & \\
\hline South & $19(59)$ & \\
\hline \multicolumn{3}{|l|}{ Gender } \\
\hline Women & $25(78)$ & \\
\hline Men & $7(22)$ & \\
\hline \multicolumn{3}{|l|}{ Professional approach } \\
\hline Cognitive-behavioural & $2(6)$ & \\
\hline Community and social & $4(13)$ & \\
\hline Ethnopsychiatry & $8(25)$ & \\
\hline Existential and humanistic & $3(9)$ & \\
\hline Psychoanalytic-dynamic & $14(44)$ & \\
\hline Systemic & $1(3)$ & \\
\hline \multicolumn{3}{|l|}{ Origin } \\
\hline Argentina & $1(3)$ & \\
\hline Brazil & $26(81)$ & \\
\hline Columbia & $1(3)$ & \\
\hline Lebanon & $1(3)$ & \\
\hline Peru & $1(3)$ & \\
\hline Syria & $1(3)$ & \\
\hline Uruguay & $1(3)$ & \\
\hline \multicolumn{3}{|l|}{ Working languages $^{\mathrm{a}}$} \\
\hline Portuguese & $32(100)$ & \\
\hline Spanish & $22(68.8)$ & \\
\hline French & $6(18.8)$ & \\
\hline English & $11(34.4)$ & \\
\hline Arabic & $2(6.3)$ & \\
\hline \multicolumn{3}{|l|}{ Attending refugees in ${ }^{a}$} \\
\hline Refugee housing & $5(15.6)$ & \\
\hline University clinic & $13(40.6)$ & \\
\hline Private practice & $3(9.3)$ & \\
\hline NGO setting & $12(38)$ & \\
\hline CRAI $^{\mathrm{b}}$ & $3(9)$ & \\
\hline
\end{tabular}

Data are total number (percentage) or mean (standard deviation) and range

${ }^{\mathrm{a}}$ Multiple responses possible

${ }^{\mathrm{b}}$ Psycho-social Centre for Refugees 
recorded and fully transcribed. To secure the anonymity of participants, all identifying information was removed, the names of participants were replaced for codes and locations of practice were collated into regions.

\section{Data Analysis}

Interview transcripts were analysed focusing on the overt meaning in the data, i.e. what is said and by whom. CQR (Hill et al. 2005) was adopted as this approach represents a systematic method to evaluate the representativeness of issues across cases. First, every interview was read thoroughly and sections related to psychological suffering of refugees were highlighted. The first author coded highlighted sections line-by-line and developed a hierarchical coding tree by collating the codes into subthemes, themes and categories. In order to assess the fit of the coding tree, the first author and two further researchers re-applied it to the interview transcripts independently and subsequentially discussed until a consensus about the codes, subthemes, themes, and their hierarchical structure was found. These steps were carried out in Portuguese (González and Lincoln 2006). The coding tree was then translated into English, using a bilingual committee (Brislin 1970). Next, the whole data set was organised into the English coding tree using the qualitative analysis software MAXQDA (VERBI-Software (2020). MAXQDA 2020[computer software]. Berlin, Germany.: VERBI Software. Retrieved from https://www.maxqda.com 2020) in order to systematically represent the frequencies of participants endorsing each theme and subtheme (Tables 2, 3). The frequency counts enable an overview of the presence of each theme in the data set (Malterud 2001). Themes were labelled "general" if they were endorsed by 31-32 participants, "typical" if they applied to 16-30 cases, "variant" for less than 16 but at least 5 cases, and "rare" if endorsed by only 1 to 4 participants (Hill et al. 2005).

\section{Researchers' Positionality}

The study's principal investigator who conducted the interviews and served as the primary coder is a PhD candidate in cultural psychology. Being of German origin, she gained awareness for challenges in post-migration settings through her own experiences of migration and academic interests in refugee studies. The fact that she is of German nationality might have, in regard to the history of colonisation (González and Lincoln 2006), impacted the extent to which participants felt at ease to articulate their perspectives. Yet, the principal investigator had worked for an extended period of time among psychologists in Brazil and was, thus, familiar with styles of communication and interaction in this context. Moreover, the other two coders of the study were Brazilian clinical psychologists which improves the likelihood that the manner in which psychologists in Brazil speak about psychological suffering was captured accurately. All three researchers have extensive experience using qualitative methods of inquiry. Informed by the literature on refugee mental health, the researchers expected participants to highlight PTSD, depression and anxiety as common mental health problems in their patients. 


\section{Results and Discussion}

\section{Refugee Patients' Backgrounds}

In order to contextualise the findings on patients' suffering, psychologists were asked to name the country of origin $(\mathrm{CoO})$ of their patients as well as additional characteristics they deemed important. In doing so, participants did not distinguish between patients' official immigration or asylum status. Thus, the CoOs reported here are of diverse immigrants, including refugees and asylum seekers. In sum, participants named 42 different CoOs (see Figs. 1). Most frequently mentioned CoOs were Venezuela, Haiti, Syria, and Colombia. Other frequently mentioned characteristics of patients were pregnant women or single mothers, lesbian, gay, bisexual, transgender, and queer people.

\section{How Do Psychologists Describe the Suffering of Their Refugee Patients?}

The following section synthesises in four categories what psychologists perceived to constitute the psychological suffering in their refugee patients (Table 2). Figure 2 displays these categories as interlinked: Currently, the refugee finds herself in a context of post-migration difficulties (upper part of the figure), her life was ruptured by the flight (zig-zag-line), the situation in the $\mathrm{CoO}$ is still present for her (forming the base of the figure) and traumatic experiences transcend the $\mathrm{CoO}$, the flight as well as the post-migration situation.

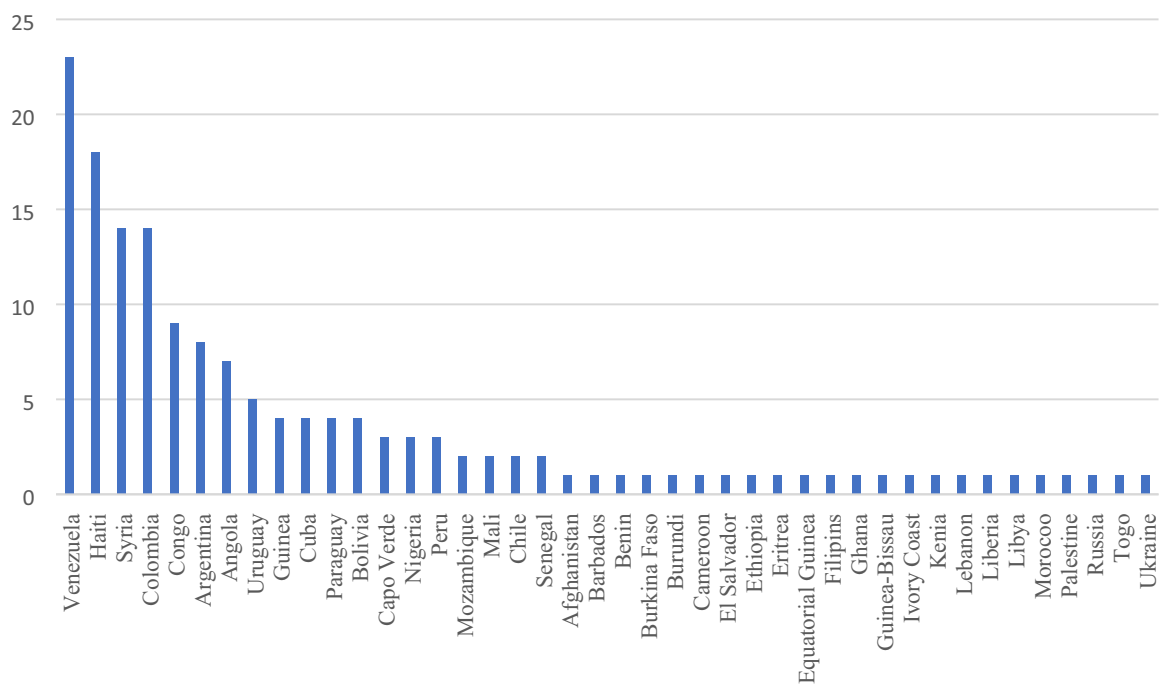

Fig. 1 Number of psychologists mentioning the respective country of origin of their (migrant and/or refugee) patients 


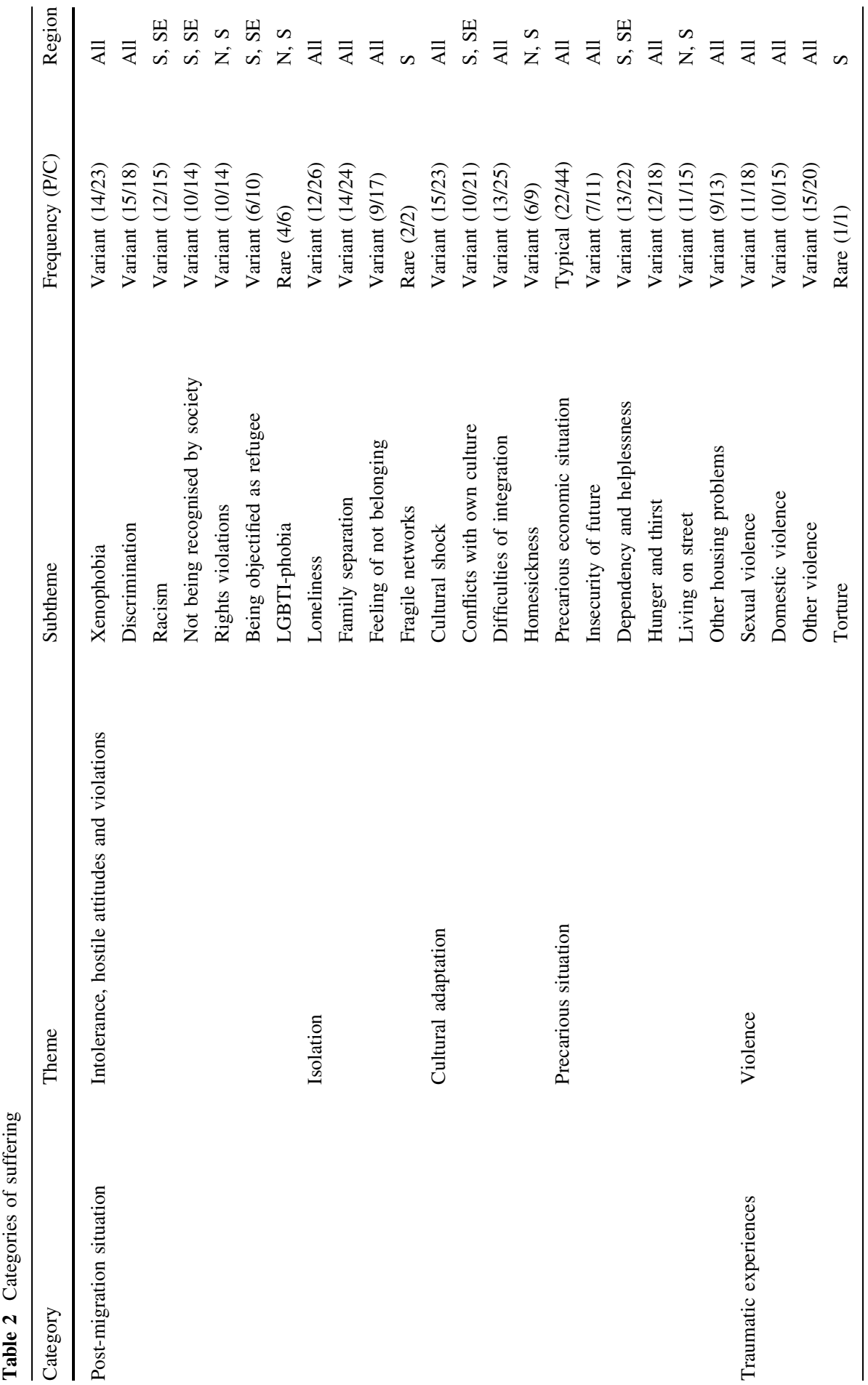




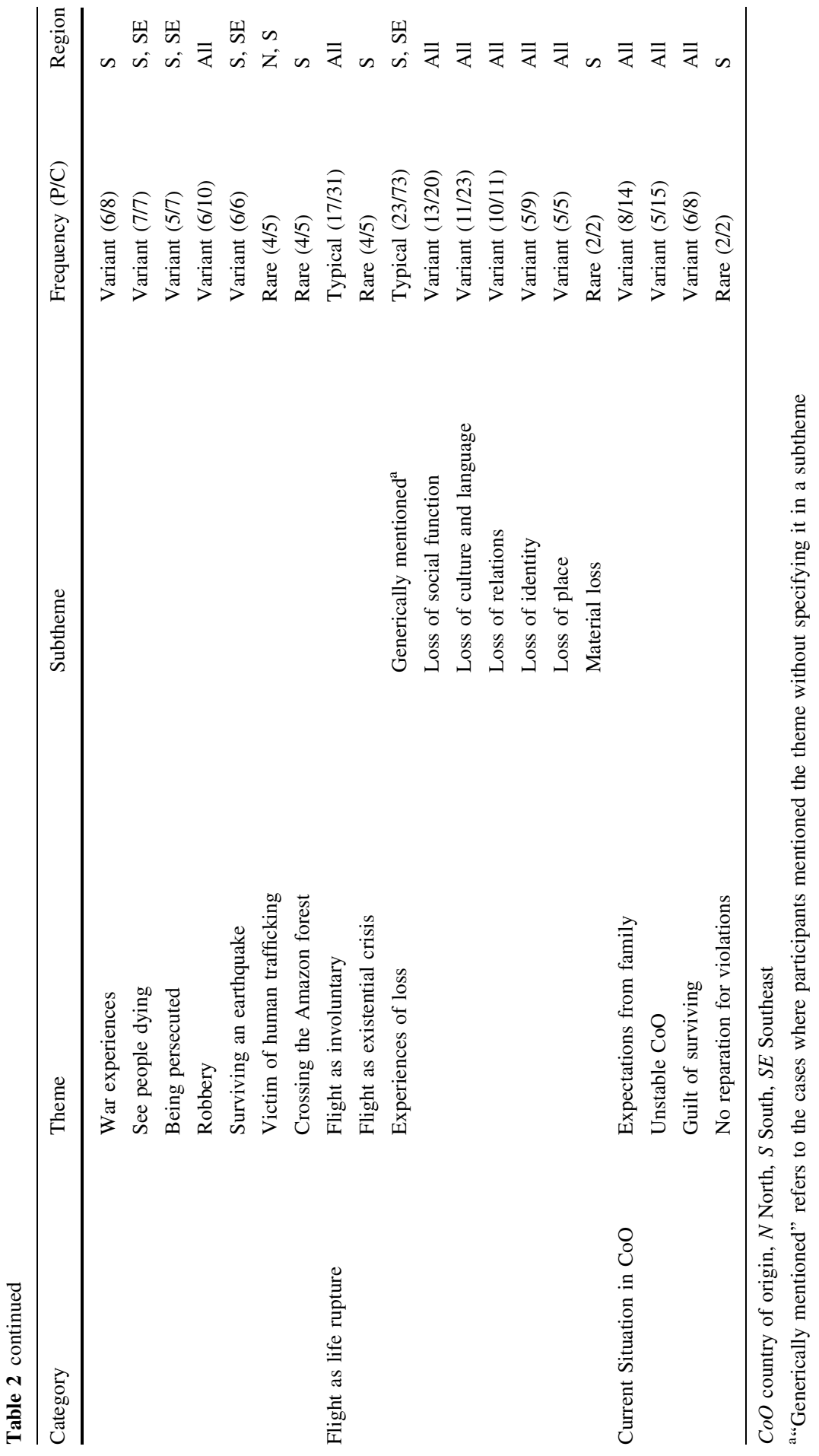




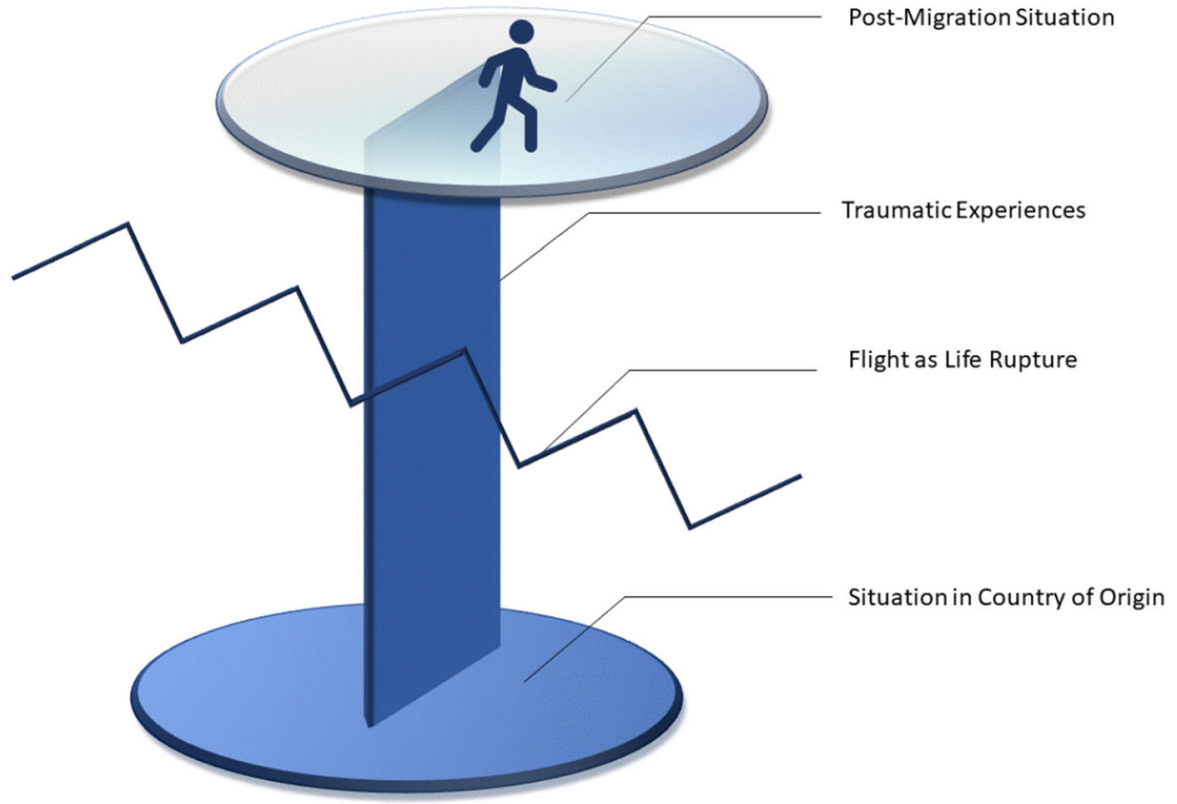

Fig. 2 Categories of Suffering. Traumatic experiences are represented as transcending the CoO, the flight as well as the post-migration situation

\section{Post Migration Situation}

All participants stressed how the post-migration context causes substantial suffering in refugee patients. This category took up the most considerable portion of all interview transcripts. The following factors were perceived as particularly impactful for patients:

\section{Hostile Attitudes, Intolerance and Rights Violations}

There is suffering for not being recognized by the other. We have many refugees here in Brazil who are black, who come from African countries or Haiti. Blacks suffer a lot from racism. Racism is very strong here. They tell me: "What do I do if I walk on the street, people start walking very fast, they don't stay on my side." That creates suffering. (P15, psychoanalytic, Age: 41, South)

All participants mentioned that their patients were suffering from experiencing hostile attitudes and intolerance, in particular by being subject to xenophobia, discrimination, racism, LGBTQ-phobia, as well as not feeling recognised by society or objectified as a refugee. Variant participants also described the human rights violations their patients were experiencing in Brazil, including physical mistreatment, (sexual) abuse and slavery work. 
Discrimination and xenophobia have been described as major obstacles for the integration of refugees in Brazil and as strongly related to the struggle of finding employment (Moreira and Baeninger 2010). Internationally, experiencing discrimination in host countries has been found to greatly impact the mental health of refugees (Bogic et al. 2012), sometimes even more than pre-migratory trauma (Beiser and Hou 2016).

\section{Isolation}

Isolation was another factor participants typically saw as part of the suffering of patients: “[...] a state of complete loneliness. She feels disconnected from people. She feels that no one will understand her. And she feels that she won't understand anyone" (P9, ethnopsychiatric, Age: 28, South). Psychologists described patients' feelings of loneliness and not-belonging and highlighted the fact that patients often suffered due to being separated from their families. Two participants mentioned that refugee patients had very fragile networks in their new context.

Social isolation has been described as a major stressor in post-migration settings (Miller and Rasmussen 2011). Eisenbruch (1991) integrated the loss of social networks and of a sense of belonging in the concept of "cultural bereavement" which he considered characteristic of forced displacement (e.g. Bhugra and Becker 2005). Reinforcing this, others have found associations between the wellbeing of displaced people and the reconstruction of social networks and a feeling of community (Summerfield 1999).

\section{Cultural Adaptation}

As a further variant factor of suffering in the post-migration situation, processes of cultural adaptation were described. Participants mentioned the patients' struggles with integrating into Brazilian society, experiencing cultural shocks and finding it hard to build relationships with Brazilians: "They report a lot of difficulty in establishing ties with people here" (P23, psychoanalytic, Age: 60, Southeast). Together with feelings of homesickness these struggles contributed to the sense of isolation in patients. Furthermore, psychologists saw some of their patients as coming into conflict with their culture of origin.

The latter may, as research suggests, be particularly impactful in individuals with families and cause intergenerational conflicts since family members can differ in their speed and way of acculturating (Droždek 2007; Leyendecker et al. 2018). There have been inconsistent results in the literature regarding the relationship of acculturation and mental health (Kartal and Kiropoulos 2016), but often cultural adaption is viewed as a cause of substantial distress in immigrants (Knipscheer and Kleber 2006; Martins-Borges 2013, 2017).

\section{Precarious Situation}

The precarious nature of the patients' context was typically perceived as a further aspect of refugees' suffering: "the precariousness of his life made him feel 
paralyzed and unable to act" (P10, community/social, Age: 27, South). Variant participants described patients fearing for basic needs, experiencing hunger or living on the street. Furthermore, participants typically highlighted the economic instability and financial troubles of patients due to a lack of stable employment and financial support structures. Variant psychologists mentioned that the precarious situation evoked feelings of helplessness and humiliation in many refugees. Participants also stressed the impact of future insecurity on patients:

The greatest suffering is the uncertainty. They are not "refugees" when they arrive. They are 'asylum seekers', a totally preliminary and provisional situation that can last three to five years. This reinforces the liminal character of migration... being in and out... which makes it impossible to build long-term plans. (P3, community/social, Age: 61, Southeast)

Even though there is no detention and deportation in Brazil (Jubilut 2006; Leão 2011) and these two aspects have been most strongly associated with future insecurities (Davidson, Murray and Schweitzer 2008; Momartin et al. 2006), participants described strong feeling of insecurity in their refugee patients. These feelings can be understood in light of a context in which refugee applications are only processed slowly, in which high rates of extreme poverty and social inequality are common (de Barros, Henriques and Mendonça 2001) and in which refugees struggle with unmet basic needs and a lack of integration structures (Knobloch 2015; Moreira and Baeninger 2010). For instance, Aydos, Baeninger and Dominguez (2008) reported that about $37 \%$ of displaced people lived on the street after arrival in Brazil. A strong association between social inequality, poverty and mental health disorders has been stressed for the general population in Brazil (Silva and Santana Santana 2012). Concerning refugees, employment and economic stability have been found highly important for good health outcomes (Bogic et al. 2012; Lindert et al. 2009; Knipscheer and Kleber 2006). The effect of future instability due to tedious asylum procedures and temporary visa on the mental health of asylum seekers is an issue of international concern (Comtesse and Rosner 2019; Davidson, Murray and Schweitzer 2008).

\section{Traumatic Experiences}

Most participants talked in some form about traumatic experiences in relation to the suffering of their patients. Patients' traumas included experiences of war, surviving an earthquake, violence and human trafficking, seeing people dying, being persecuted, robbed, and crossing the Amazon forest:

She entered the Amazon forest and spent days on a boat in a river with crocodiles and with others who assaulted her. In this country, on her first stop after Cuba, she worked in slavery-like conditions, she was even locked-in at her work, and she had to escape. (P12, ethnopsychiatric, Age: 27, South)

The types of trauma experienced depended on patients' trajectories and their CoO. For instance, psychologists who attended mainly Haitians often described the impacts of surviving an earthquake. 


\section{Flight as Life Rupture}

A common issue is grief. Grief in relation to the country, to the culture, to the recognition of identity. To their life project, that was abruptly interrupted. (P24, ethnopsychiatric, Age: 33, South).

Most psychologists perceived a life rupture due to the involuntary flight as part of the suffering of their patients. The flight came with many losses that sometimes lead to the experience of existential crisis.

Leaving one's home involuntarily without preparation for the ruptures that this flight will cause has been described as a risk factor for mental health (MartinsBorges 2013). Research has shown that experiencing loss, such as of one's home and the sense of social belonging and connection to a land and its symbols is associated with refugees' mental health outcomes (Davidson, Murray and Schweitzer 2008). The loss of social belonging also forms an essential element of the concept of cultural bereavement (Droždek 2007; Eisenbruch 1991).

\section{Current Situation in Country of Origin (CoO)}

Finally, psychologists suggested patients' suffering was dependent on what was happening in their CoO. First, they linked patients' distress to the expectations from relatives that remained in the $\mathrm{CoO}$. Second, patients suffered when the situation in their $\mathrm{CoO}$ was still unstable, dangerous and difficult for those who had stayed: "First of all there is the family left behind in Venezuela. I hear a lot that it's like a type of guilt: 'I am here eating, I am here sleeping, and my family is starving on the street'" (P22, psychoanalytic, Age: 43, Southeast). Some patients were described to be constantly worrying about the well-being of their relatives in the $\mathrm{CoO}$ and to be feeling guilty for surviving and leaving people behind. Furthermore, two psychologists saw the fact that patients did not receive reparations from their $\mathrm{CoO}$ for violations they had experienced as impeding the healing process.

Many of the CoOs of participants' patients, such as Venezuela and Haiti, continue in precarious situation of violence, famine and misery (de Oliveira, Yazdani and Gomes 2019). The literature shows that refugees from countries whose conflicts are still unresolved have worse mental health outcomes (Porter and Haslam 2005) and a sort of "survivor guilt" has been reported as a common phenomenon among refugees (Eisenbruch 1991; Martins-Borges 2013).

\section{Which Mental Health Disorders and Symptoms Do Psychologists Perceive to Be Most Common Among Their Refugee Patients?}

The following section focuses on the mental disorders and symptoms participants most commonly perceived in their patients (see Table 3; Fig. 3). However, and in order to contextualise these results, we first report on whether and in which way participants made use of mental disorder classifications (MDC). 


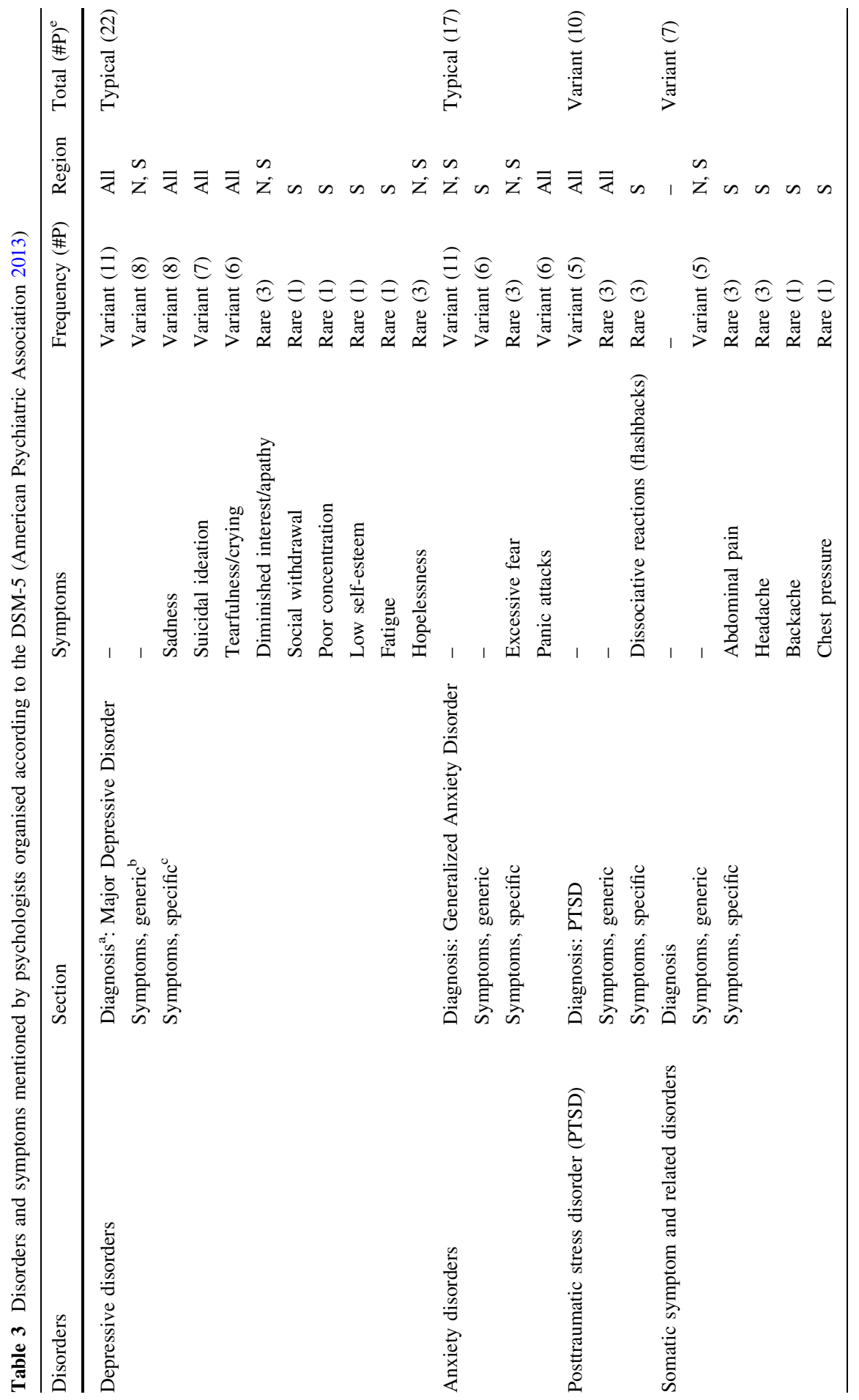




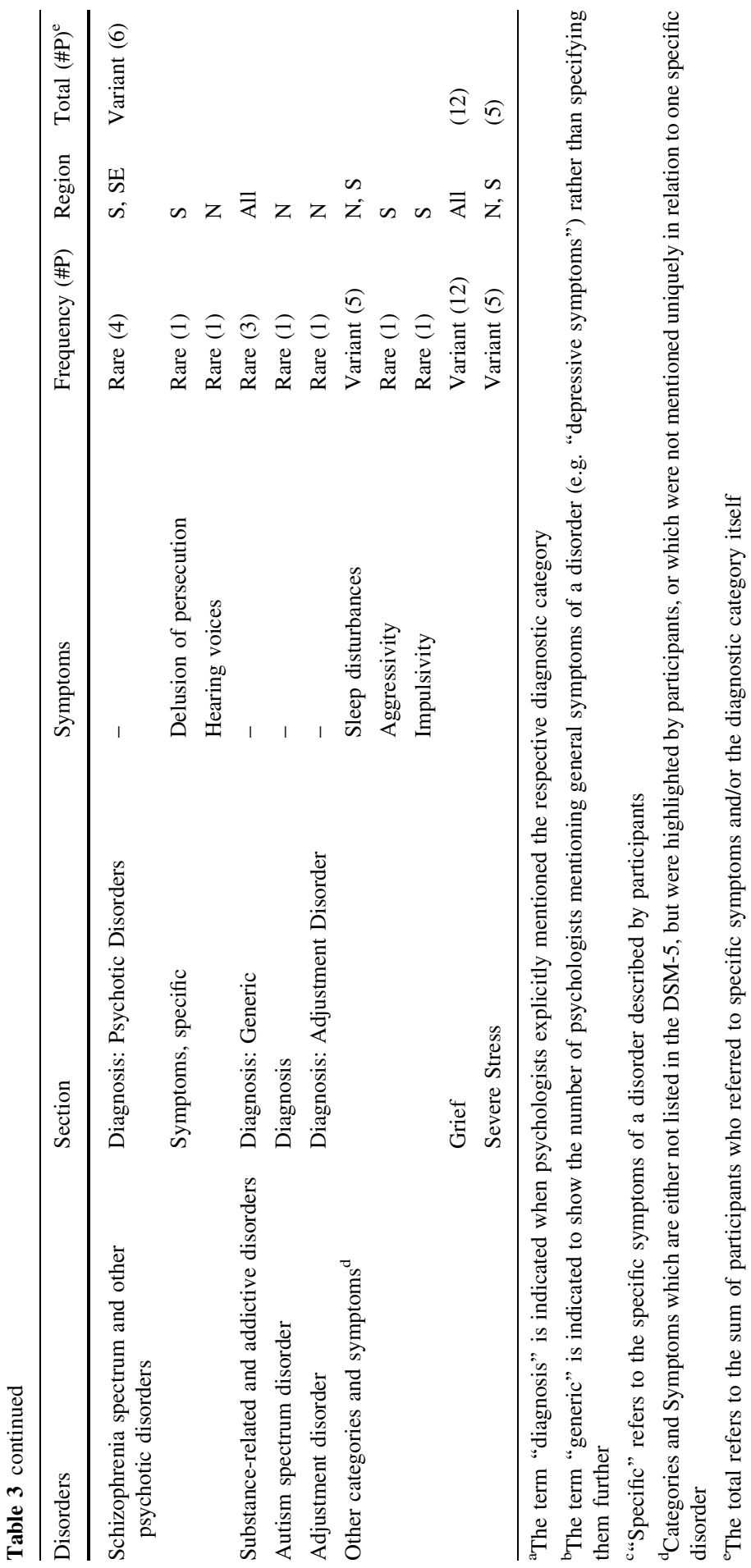


Fig. 3 Most frequently mentioned symptoms or states. The number indicates the total of psychologists who referred to the respective symptom or state

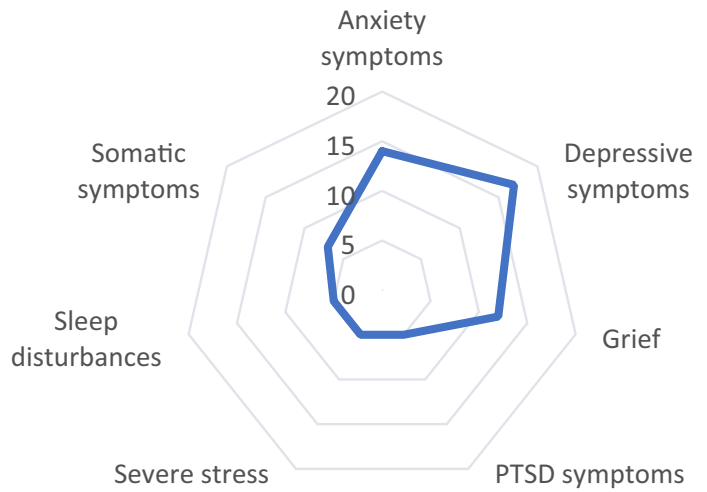

Symptoms/States

\section{Use of Mental Disorder Classifications}

Prevailing among participants were critiques of MDCs with 18 stating they did not use psychiatric diagnostic manuals such as the DSM-5 at all.

I don't think diagnostics have any function. Because they're Western diagnostics. If I am talking about understanding the constitution of a subject in a cultural dimension, the way he suffers, and what he presents as suffering, is also a narrative of his culture. And who made the diagnoses were Westerners. From a biomedical perspective. (P6, ethnopsychiatric, Age: 28, South)

I don't work with diagnostics at all. I think they suit the pharmaceutical industry a lot because they frame the subject by his symptom [...] that human part of medicine, in the case of these diagnostic manuals, has been lost. Psychiatrists, for example, have become prescribers of pain medication. There is no 'listening' anymore. (P17, psychoanalytic, Age: 47 years, South)

Certainly, these opinions might also reflect the fact that of the participants $44 \%$ followed psychoanalytic/-dynamic, 25\% ethnopsychiatry and 16\% community, social or systemic approaches (Table 1) - therapeutic orientations which do not place their emphasis on diagnostic categories (e.g. Guzder 2014; Wolitzky 2020). Some psychologists indicated the use of diagnostic strategies, but rather than applying categorical manuals such as the DSM-5, they were oriented towards psychoanalytic structural diagnostic or the axis of DSM-IV. These approaches seemed more flexible, continuous and more appropriate to them. The participants who made use of manuals such as the DSM-5 $(n=14)$, indicated employing them carefully and mostly in order to communicate with other professionals. Participants showed themselves aware of cultural and languages differences that might cause wrongful diagnosis, but they did not see this as a difficulty. Rather participants stressed that these differences made the careful and flexible use of diagnostic manuals even more important. This finding was especially pronounced in the 
participants who had studied cultural psychology and worked with ethnopsychiatry; meanwhile it was also represented among other participants.

A critical use of Western psychiatric diagnostic manuals is not uncommon in Latin American countries (Parra 2013). Internationally, critiques of these manuals have been made, especially concerning their universal applicability (Droždek 2007; Summerfield 1999), since the manuals themselves represent cultural products (Gone and Kirmayer 2010) and their use can lead to miss-interpretation of suffering (Kizilhan 2006; Wohlfahrt and Zaumseil 2006). Some have also posed the more general question if MDC necessarily leads to an improvement in our understanding of effective interventions (Kirmayer and Sartorius 2007). In line with many of the participants of the present study, Aveline (2005:158) argues, that the categorical perspective of psychological suffering often does not fit the "problems in living" of patients. To a large extent the interviewed psychologists embraced the idea that the focus on classified disorders was insufficient to guide their practice, as patients struggled with the "social suffering" discussed in the previous section, i.e. contextual predicaments stemming e.g. from experiencing racism, not necessarily from psychiatric disorders (Guzder 2014; Kleinman, Das and Lock 1997).

I haven't identified depressive cases. The point is, there are cases of sadness, but if you do a little more analysis, you realize that it's a sadness of the whole process they are experiencing in their lives at the moment. (P16, community/social, Age: 29, South).

Alternative strategies for making sense of the suffering of patients in transcultural encounters have been proposed in the literature, such as the DSM-5 Cultural Formulation Interview (APA 2013) or the McGill Illness Narrative Interview (Groleau, Young and Kirmayer 2006). This latter interview aims to elicit patients' own narratives of their suffering in order to find pathways to care that are in line with their experience (Groleau, Young and Kirmayer 2006).

\section{Mental Health Disorders and Symptoms}

Despite critiques of MDCs, all psychologists participated in a description of the most common symptoms and disorders of their refugee patients. The descriptions are elaborated here and represented in Fig. 3 and Table 3.

\section{Depressive Disorders and Symptoms}

Typically, psychologists mentioned depressive disorders and symptoms as common among their patients. Described depressive symptoms included constant crying, sadness and apathy. Three participants also referred to a deep despair in patients which they perceived as an existential hopelessness. Furthermore, suicidal ideation was often mentioned in combination with depression.

Internationally, depression has been reported with high prevalence rates among refugees (Lindert et al. 2009). In Brazil, a study of Haitian immigrants yielded that depressive symptoms were in the clinical range in $10.6 \%$ of participants (Brunnet et al. 2018). A study of Bolivian immigrants in São Paulo indicated the high 
probability of a mental disorder in more than half of the participants, with depressive and anxiety symptoms having the highest prevalence (Bustamante Ugarte et al. 2019).

However, many participants of the present study questioned the distinction between depressive disorder and grief. 12 of the interviewed psychologists explicitly stated they preferred to talk in terms of grief as opposed to depressive disorder and to consider their patients' mental states, which resembled depressive phases, to be normal reactions to the many losses the refugees had faced.

The refugee suffers from grief. From a succession of bereavements. The refugee's suffering revolves around loss. The loss of a known place, the loss of a group of people, of relationships, the loss of a social function. So, I think in terms of psychic suffering the most striking one is loss and grief. (P9, ethnopsychiatric, 28 years, South)

In the literature there has been a resurgence of interest in the construct of grief, especially concerning refugee patients (Comtesse and Rosner 2019; Momartin et al. 2004; Silove, Ventevogel and Rees 2017), since loss is such a common experience among refugees and linked to their mental health outcomes (Davidson, Murray and Schweitzer 2008).

\section{Anxiety Disorders and Symptoms}

Typically, psychologists also described anxiety symptoms and disorders as common in their refugee patients:

The most common psychological suffering... Very high anxiety. Depression. Absurd. Panic attacks. [...] Anxiety and panic because they find themselves in a dangerous situation and are always alert. And that means stress as well. They are always afraid that somebody could rob them, the family is starving and in need of them in Venezuela. (P1, existential/humanistic, Age: 31, North)

Research has found heightened levels of anxiety in asylum seekers (Silove et al. 1997). Lindert, et al.'s (2009) meta-analysis showed a combined anxiety prevalence rate of $40 \%$ in refugees and more recently, Turrini et al. (2017) reported that anxiety and depression in refugees were at least as frequent as PTSD and affected on average one out of three refugees. Presumably, anxiety states result from refugees' past experience, but also from the insecurity and instability in their postmigration situation: "Anxiety disorders are very present. But for complex reasons, not for certain permanent core beliefs, but due to the external stress that is permanent" (P20, cognitive-behavioural, 43 years, South). In the case of Brazil, one might question if heightened anxiety is specific to refugees or also common in the general population and a reflection of a widespread sense of political, economic and personal insecurity. For instance, in São Paulo anxiety disorders were found to affect almost $20 \%$ of the general population (Andrade et al. 2012). Meanwhile, the study by Andrade et al. used criteria of the DSM-IV which were criticized by many participants in the present study. Furthermore, it is likely that there are enormous differences in the anxiety rates of the general Brazilian population depending of the 
location of research-São Paulo, the most populous city of Brazil and South America might differ considerably in this aspect compared to a rural region in Minas Gerais, for instance.

\section{Posttraumatic Stress Disorder (PTSD)}

Ten participants spoke of PTSD or related symptoms among their patients: "There's posttraumatic stress which we end up working with a lot. You see a lot of it. Posttraumatic stress due to displacement, due to violence" (P1, existential/ humanistic, Age: 31, North). At the same time, 29 psychologists used the word "traumatic" when describing their patients' experiences: "Many were raped and robbed on their way. They got here only with their cloths on their body - the experience from there to here is traumatic for almost everybody" (P29, psychoanalytic, Age: 23, North).

The finding that most participants described refugees' traumas but relatively few mentioned PTSD might, firstly, be due to an epistemological difference in participants' concepts of trauma and the concept underlying the PTSD diagnosis. When participants were invited to explain their understanding of trauma, most psychologists defined it as an event that did not have a psychic representation and was "unbearable to tell". This demonstrates a psychoanalytic understanding of trauma (Levine 2014). A second explanation might be that, even though, robust associations have been made between pre-flight trauma and the mental health of refugees (Davidson, Murray and Schweitzer 2008; Silove et al. 1997) and refugees show higher rates of PTSD than the general population (Fazel, Wheeler and Danesh 2005), most people who have survived traumas do not develop PTSD (Bisson et al. 2015). Furthermore, traumas linked to profound losses might, in the long term, rather evoke depressive than PTSD symptoms (Momartin et al. 2004). Finally, a closer analysis of the transcripts showed that, in relation to the aforementioned critical attitude towards MDC, many participants were reluctant to use the PTSD category as they worried that this would reduce patients' suffering to past events and turn it into an individualised and "medical" problem, thus neglecting its sociopolitical dimension: "Of course, trauma means that the subject has experienced a terrible traumatic scene. I'm not saying otherwise. I am saying that the sociopolitical situation promotes trauma and is something that stifles the subject in various ways" (P27, psychoanalytic, Age: 33, Southeast).

As with most diagnostic categories, the concept of PTSD is a product of EuroNorth-American culture, context and history (Kirmayer et al. 2015), but the discourse around it has reached diverse cultural realties globally (Argenti-Pillen 2000). One might wonder if participants' critique of the concept of PTSD, i.e. implying an individualisation of trauma, could be related to the recent history of dictatorship in Brazil which involved experiences of collective traumas (Kevers et al. 2016). However, the argument, that PTSD is too much focused on past traumas and disregards the socio-political context in which traumas occur, has been used internationally, too, as one aspect of the considerable critique of PTSD (Droždek 2007; Kevers et al. 2016; Summerfield 1999, 2008). Some authors state this focus implies neglecting the complexity of the refugee situation and missing out on the 
opportunity to better mental health outcomes in refugees by changing present conditions in host countries (Watters 2001). This was also stressed by the participants in the current study who, in line with Cleveland, Rousseau and Guzder (2014), consistently brought up the present post-migration situation as interplaying and exacerbating past traumas:

In the case of the Syrians, we think that we will work with war traumas. But none of them ask for trauma care in the sense we imagine. All of them have other challenges, especially the daily challenge of living as a refugee here in Brazil. (P19, systemic, Age: 30, South)

\section{Other Mental Disorders and Symptoms}

Other mental health conditions described by more than one psychologist included somatic symptoms, psychotic disorders and symptoms, severe stress, sleep disturbances and substance abuse: "There are a lot of cases of alcoholism, in women too" (P30, existential/humanistic, Age: 40, North).

Most of these disorders and symptoms have been described in previous studies concerning the mental health of refugee patients (Silove, Ventevogel and Rees 2017). For instance, a number of studies has linked PTSD symptoms to psychotic symptoms in refugees (Nygaard, Sonne and Carlsson 2017) and reports of somatic symptoms are common among immigrant, but also among most general patients suffering from depression or anxiety (Kirmayer 2001).

\section{Limitations and Suggestions for Future Research}

The results of the present study have to be considered in light of certain limitations. Firstly, it is important to note that participants reported not on refugees in general, but on their refugee patients, i.e. people who seek psychological help as they find themselves in troubling states. To obtain a broader picture of the mental health of refugees in Brazil, future studies are needed that focus on refugees outside of clinical settings.

Secondly, findings represent the subjective evaluations of psychologists who treat refugees in Brazil and do not represent quantifiable or generalisable data. For instance, participants might have been more likely to report on extreme cases when asked to describe their patients' psychological suffering. However, as the first study investigating the suffering of refugee patients across Brazilian states, the results provide valuable insights into common social and mental health problems faced by this group and a base for further epidemiological and quantitative studies. Potentially lower rates of PTSD diagnosis in Brazil for example, might also result from professionals' critical attitude towards mental health categorisation and the PTSD concept.

Finally, this study focused on psychologists' experiences in treating heterogenous patients from various countries with diverse reasons for migration, heterogenous experiences of flight and post-migration stressors, and varying lengths of stay in Brazil. These factors and their complex interaction may play a crucial role in 
shaping patients' mental health (Turrini et al. 2017). Also, even though participants were asked to report on their refugee patients, it is unclear if their descriptions only related to people with the respective official asylum status. Many of the psychologists also treated general immigrants and may not have differentiated between patients in relation to their immigration status when reporting on their suffering. This, as well as the diverse interview settings ranging from the South to the extreme North of Brazil, is likely to have impacted participants' descriptions of their patients' suffering (Andrade et al. 2012). However, the analysis of the data did not show any major differences in perspectives on patients' suffering related to location of practise (Table 2), except for traumatic war experiences which were only described by psychologists in the South and Southeast. This might be explained by the fact that there are more Syrians applying for asylum in these regions (CONARE 2020). Patients in the North came almost exclusively from Venezuela, where there is a humanitarian crisis (CONARE 2020), but not a situation of war as in Syria. Further studies could explore the differences in suffering related to diverging asylum status and psychologists' location of work in more detail.

\section{Conclusion}

To our knowledge, this study is the first to investigate psychologists' perspectives on the suffering of their refugee patients in diverse Brazilian states. It confirms previous findings highlighting depression and anxiety as common conditions among refugee patients (Lindert et al. 2009), but also supports concepts such as prolonged grief (Comtesse and Rosner 2019; Momartin et al. 2004) and cultural bereavement (Eisenbruch 1991) as valuable alternatives to common mental disorder classifications in refugees. Additionally, the present study provides evidence for a prevailing critical perspective on mental disorder classifications, such as the DSM-5, among psychologists in Brazil. Many of the participants thought of the suffering of refugee patients in relation to their social and political context and post-migration situation, rather than in relation to specific diagnostic categories. This reinforces the call to acknowledge the socio-political suffering of refugees (Droždek 2007; da Silva Machado, Barros and Martins-Borges 2019) and increases the importance of strategies that, in order to foster the mental health of refugees, address current stressors in post-migration settings, such as discrimination (Duden and MartinsBorges, 2021).

Acknowledgements Gesa Duden gratefully acknowledges a Research Fellowship through the HansBöckler-Stiftung (Germany). Lucienne Martins-Borges acknowledges the financial support through the Conselho Nacional de Desenvolvimento Científico e Tecnológico - CNPq (Brazil).

Funding Open Access funding enabled and organized by Projekt DEAL.

\section{Declarations}

Conflict of interest The authors report no conflict of interest. 
Open Access This article is licensed under a Creative Commons Attribution 4.0 International License, which permits use, sharing, adaptation, distribution and reproduction in any medium or format, as long as you give appropriate credit to the original author(s) and the source, provide a link to the Creative Commons licence, and indicate if changes were made. The images or other third party material in this article are included in the article's Creative Commons licence, unless indicated otherwise in a credit line to the material. If material is not included in the article's Creative Commons licence and your intended use is not permitted by statutory regulation or exceeds the permitted use, you will need to obtain permission directly from the copyright holder. To view a copy of this licence, visit http:// creativecommons.org/licenses/by/4.0/.

\section{References}

Agência Brasil

2020, June 10th Brasil tem 43 mil pessoas reconhecidas como refugiadas, diz Conare. https:// agenciabrasil.ebc.com.br/direitos-humanos/noticia/2020-06/brasil-tem-43-mil-pessoasreconhecidas-como-refugiadas-diz-conare.

American Psychiatric Association

2013 Diagnostic and Statistical Manual of Mental Disorders. 5th Edition. Arlington: American Psychiatric Association. https://doi.org/10.1176/appi.books.9780890425596.

Andrade, L.H., Y.-P. Wang, S. Andreoni, C.M. Silveira, C. Alexandrino-Silva, E.R. Siu, R. Nishimura, James C. Anthony, Wagner Farid Gattaz, Ronald C. Kessler, and Maria Carmen Viana

2012 Mental disorders in Megacities: Findings from the São Paulo Mental Health Survey, Brazil. PLoS ONE 7(2):e31879.

Argenti-Pillen, A.

2000 The Discourse on Trauma in Non-western Cultural Contexts. In International Handbook of Human Response to Trauma, pp. 87-102. New York: Springer.

Assis, G.O.

2018 A nova lei de migração no Brasil: Avanços e desafios. In Migrações Sul-Sul. R. Baeninger, L.M. Bogus, J.B. Moreira, L.R. Vedovato, D. Fernandes, M.R. Souza, C.S. Baltar, R.G. Peres, T.C. Waltman, L.F.A. Magalhães, eds., pp. 609-623. Campinas: Elza Berquó-NEPO/UNICAMP.

Aveline, M.

2005 The Person of the Therapist. Psychotherapy Research 15(3):155-164.

Aydos, M., R. Baeninger, and J.A. Dominguez

2008 Condições de Vida da População Refugiada no Brasil: trajetórias migratórias e arranjos familiares. In Trabalho apresentado no III Congresso da Associação Latino Americana de População. Córdoba.

Barros, A.F.O., and L. Martins-Borges

2018 Reconstrução em movimento: Impactos do terremoto de 2010 em imigrantes haitianos. Psicologia: Ciência e Profissão 38(1):157-171.

Beiser, M., and F. Hou

2016 Mental Health Effects of Premigration Trauma and Postmigration Discrimination on Refugee Youth in Canada. The Journal of Nervous and Mental Disease 204(6):464-470.

Bhugra, D., and M.A. Becker

2005 Migration, Cultural Bereavement and Cultural Identity. World Psychiatry 4(1):18.

Bijit Abde, K.

2012 El proceso de integración social de los refugiados palestinos reasentados en región de Valparaiso, Chile. Si Somos Americanos 12(1):155-180.

Bisson, J.I., S. Cosgrove, C. Lewis, and N. Roberts

2015 Post-traumatic Stress Disorder. BMJ 351:h6161.

Bogic, M., D. Ajdukovic, S. Bremner, T. Franciskovic, G. Galeazzi, A. Kucukalic, D. Lecic-Tosevski, Nexhmedin Morina, Mihajlo Popovski, Matthias Schützwohl, Duolao Wang, and Stefan Priebe

2012 Factors Associated with Mental Disorders in Long-Settled War Refugees: Refugees from the Former Yugoslavia in Germany, Italy and the UK. The British Journal of Psychiatry 200(3):216223. 
Bógus, L.M.M., and V.M. Rodrigues

2011 Os refugiados e as políticas de proteção e acolhimento no Brasil: História e Perspectivas. Dimenses 27:101-114.

Braga Bezerra, C., L. Martins-Borges, and M. Cunha Pereira

2019 Filhos das fronteiras: Revisão de literatura sobre imigração involuntária, infância e saúde mental (Children of the Borders: Literary Review Regarding Involuntary Immigration, Childhood and

Brislin, R.W. Mental Health). Revista CES Psicología 12(2):26-40.

1970 Back-translation for Cross-Cultural Research. Journal of Cross-Cultural Psychology 1(3):185216.

Brunnet, A.E., L.T. Bolaséll, J.L. Weber, and C.H. Kristensen

2018 Prevalence and Factors Associated with PTSD, Anxiety and Depression Symptoms in Haitian Migrants in Southern Brazil. International Journal of Social Psychiatry 64(1):17-25.

Bustamante Ugarte, L.H., R.O. Cerqueira, F. De Marzio, K.P. Leite, T.D. Cadurin, E. Leclerc, A.O.R. Vistorte, Sara Evans-Lacko, and Elisa Brietzke

2019 Barriers to Care and Psychopathology Among Bolivian Migrants Living in São Paulo, Brazil. Transcultural Psychiatry 57(1):71-80.

Carrasco García, N.

2010 Necesidades especficas de protección de los niños, niñas y adolescentes colombianos refugiados en Ecuador. Revista CES psicologia 3(1):33-44.

Cleveland, J., C. Rousseau, and J. Guzder

2014 Cultural Consultation for Refugees. In Cultural Consultation, pp. 245-268. New York: Springer.

Comtesse, H., and R. Rosner

2019 Prolonged Grief Disorder Among Asylum Seekers in Germany: The Influence of Losses and Residence Status. European Journal of Psychotraumatology 10(1):1591330.

CONARE

2020 Refúgio em Números, 5th edition. Ministério da Justiça e Segurança Pública, Brazil.

Davidson, G.R., K.E. Murray, and R. Schweitzer

2008 Review of Refugee Mental Health and Wellbeing: Australian Perspectives. Australian Psychologist 43(3):160-174.

da Silva Machado, G., A.F.O. Barros, and L. Martins-Borges

2019 A escuta psicológica como ferramenta de integração: práticas clinicas e sociais em um Centro de Referência de Atendimento a Imigrantes em Santa Catarina. Revista Interdisciplinar da Mobilidade Humana 27(55):79-96.

de Barros, R.P., R. Henriques, and R. Mendonça

2001 A estabilidade inaceitável: desigualdade e pobreza no Brasil. Textos para Discussão, IPEA $800: 1-24$

de la Parra, G.

2013 Psychotherapy Research in Developing Countries: The Case of Latin America. Psychotherapy Research 23(6):609-623.

de Moraes Weintraub, A.C. Andrade

2012 Estudos sobre refugiados publicados no brasil na década de 2000. Avá. Revista de Antropología 21:1-19.

de Oliveira, A.T.R.

2017 Nova lei brasileira de migração: avanços, desafios e ameaças. Revista Brasileira de Estudos de População 34:171-179.

de Oliveira, R.W., L. Yazdani, and C.M. Gomes

2019 Do Refúgio à Garantia à Saude: Perspectivas (Des) coloniais. Saúde em Redes 5(2):315-323.

da Teixeira, S.R., F. Lotufo Neto, and N. Skokauskas

2013 Child and Adolescent Refugee Mental Health in Brazil: Literature Review and a Family Case Report. Adolescent Psychiatry 3(1):46-51.

Droždek, B.

2007 The Rebirth of Contextual Thinking in Psychotraumatology. In Voices of Trauma. B. Droždek and J.P. Wilson, eds., pp. 1-26. Boston: Springer.

Duden, G.S., Martins-Borges, L.

2021 Psychotherapy with refugees-Supportive and hindering elements. Psychotherapy Research 31(3):402-417. 
Eisenbruch, M.

1991 From Post-traumatic Stress Disorder to Cultural Bereavement: Diagnosis of Southeast Asian Refugees. Social Science and Medicine 33(6):673-680.

Fazel, M., J Wheeler, and J. Danesh

2005 Prevalence of Serious Mental Disorder in 7000 Refugees Resettled in Western Countries: A Systematic Review. The Lancet 365(9467):1309-1314.

Gergen, K.J., R. Josselson, and M. Freeman

2015 The Promises of Qualitative Inquiry. American Psychologist 70(1):1.

González, E., and Y. Lincoln

2006 Decolonizing Qualitative Research: Non-traditional Reporting Forms in the Academy. Forum: Qualitative Social Research. https://doi.org/10.17169/fqs-7.4.162.

González, M.E.

2018 Psicanálise no século XXI: um estudo sobre universidades do Rio de Janeiro e Buenos Aires. Estudos e Pesquisas em Psicologia 18(4):1175-1194.

Groleau, D., A. Young, and L.J. Kirmayer

2006 The McGill Illness Narrative Interview (MINI): An Interview Schedule to Elicit Meanings and Modes of Reasoning Related to Illness Experience. Transcultural Psychiatry 43(4):671-691.

Guzder, J.

2014 Family Systems in Cultural Consultation. In Cultural Consultation, pp. 139-161. New York: Springer.

Hall, G.C.N., T. Yip, and M.A. Zárate

2016 On Becoming Multicultural in a Monocultural Research World: A Conceptual Approach to Studying Ethnocultural Diversity. American Psychologist 71(1):40.

Hill, C.E., S. Knox, B.J. Thompson, E.N. Williams, S.A. Hess, and N. Ladany

2005 Consensual Qualitative Research: An Update. Journal of Counseling Psychology 52(2):196-205. Jibrin, M.

2017 Acolhimento psicológico de imigrantes involuntários: um encontro com a alteridade. Master's Thesis, Universidade Federal de Santa Catarina. https://repositorio.ufsc.br/bitstream/handle/ 123456789/182702/349133.pdf?sequence=1.

Jubilut, L.L.

2006 Refugee Law and Protection in Brazil: A Model in South America?. Journal of Refugee Studies 19(1):22-44.

Kartal, D., and L. Kiropoulos

2016 Effects of Acculturative Stress on PTSD, Depressive, and Anxiety Symptoms Among Refugees Resettled in Australia and Austria. European Journal of Psychotraumatology 7(1):28711.

Kevers, R., P. Rober, I. Derluyn, and L. De Haene

2016 Remembering Collective Violence: Broadening the Notion of Traumatic Memory in Postconflict Rehabilitation. Culture, Medicine, and Psychiatry 40(4):620-640.

Kirmayer, L.J.

2001 Cultural Variations in the Clinical Presentation of Depression and Anxiety: Implications for Diagnosis and Treatment. Journal of Clinical Psychology 62:22-28.

Kirmayer, L.J., and D. Pedersen

2014 Toward a New Architecture for Global Mental Health. Transcultural Psychiatry 51(6):759-776.

Kirmayer, L.J., and N. Sartorius

2007 Cultural Models and Somatic Syndromes. Psychosomatic Medicine 69(9):832-840.

Kirmayer, L.J., C. Rousseau, G.E. Jarvis, and J. Guzder

2015 The Cultural Context of Clinical Assessment. In Psychiatry. 4th Edition. A. Tasman, J. Kay, J. Lieberman, M. First, and M. Riba, eds., pp. 54-66. New York: Wiley.

Kizilhan, I.

2006 Psychotherapieforschung für Migranten. In W. Machleidt, R. Salman, \& I. T. Callies eds., Sonnenberger Leitlinien. Integration von Migranten in Psychiatrie und Psychotherapie. Erfahrungen und Konzepte in Deutschland und Europa (Vol. 4), pp. 159-168. Berlin: VWB: Verlag für Wissenschaft und Bildung.

Kleinman, A.

1980 Patients and Healers in the Context of Culture: An Exploration of the Borderland Between Anthropology, Medicine, and Psychiatry (Vol. 3). Berkeley: Univ of California Press.

Kleinman, A., V. Das, and M.M. Lock

1997 Social Suffering. Berkeley: Univ of California Press. 
Knipscheer, J., and R. Kleber

2006 The Relative Contribution of Posttraumatic and Acculturative Stress to Subjective Mental Health Among Bosnian Refugees. Journal of Clinical Psychology 62:339-353. https://doi.org/10.1002/ jclp. 20233.

Knobloch, F.

2015 Impasses no atendimento e assistência do migrante e refugiados na saúde e saúde mental. Psicologia USP 26(2):169-174.

Leão, R.Z.R.

2011 CONARE: Balanço de seus 14 anos de existência. In A. de Carvalho Ramos, G. Rodrigues, \& G. A. de Almeida eds., 60 anos de ACNUR (p. 69). São Paulo: Editora CL-A Cultural.

Levine, H.B.

2014 Psychoanalysis and Trauma. Psychoanalytic Inquiry 34(3):214-224.

Leyendecker, B., N. Cabrera, H. Lembcke, J. Willard, K. Kohl, and O. Spiegler

2018 Parenting in a New Land. European Psychologist 23:55-71.

Liberona Concha, N., and E. López San Francisco

2018 Crisis del sistema humanitario en Chile. Refugiadas colombianas deslegitimadas en la frontera norte. Estudios Atacameños 60:193-212.

Lindert, J., O.S. von Ehrenstein, S. Priebe, A. Mielck, and E. Brähler

2009 Depression and Anxiety in Labor Migrants and Refugees-A Systematic Review and Metaanalysis. Social Science and Medicine 69(2):246-257.

Lodetti, M.B.

2018 Continuidade partida: impactos psicológicos da imigração em refugiados sirios residentes na Grande Florianópolis. Master's Thesis, Universidade Federal de Santa Catarina, Brazil. https:/ repositorio.ufsc.br/bitstream/handle/123456789/198184/PPSI0816-D.pdf?sequence=$1 \&$ is Allowed=y.

Malterud, K.

2001 Qualitative Research: Standards, Challenges, and Guidelines. The Lancet 358(9280):483-488.

Martins-Borges, L.

2013 Migração involuntária como fator de risco à saúde mental. Revista Interdisciplinar da Mobilidade Humana 21(40).

Martins-Borges, L.

2017 Migrações involuntárias e impactos psíquicos: a mediação da cultura. In Sujeito contemporâneo. Saúde e trabalho: Múltiplos olhares. R.S. Peres, F. Hashimoto, M.M. Casadore, and M.V. Braz, eds., pp. 169-186. São Carlos: Edufscar.

Martins-Borges, L., M.B. Lodetti, M. Jibrin, and J.-B. Pocreau

2019 Inflexes epistemológicas: a Etnopsiquiatria. Fractal: Revista de Psicologia 31:249-255.

Meuser, M., and U. Nagel

2009 The Expert Interview and Changes in Knowledge Production. In Interviewing Experts, pp. 17-42. Heidelberg: Springer.

Miller, K.E., and A. Rasmussen

2010 War Exposure, Daily Stressors, and Mental Health in Conflict and Post-conflict Settings: Bridging the Divide Between Trauma-Focused and Psychosocial Frameworks. Social Science and Medicine 70(1):7-16.

Momartin, S., D. Silove, V. Manicavasagar, and Z. Steel

2004 Complicated Grief in Bosnian Refugees: Associations with Posttraumatic Stress Disorder and Depression. Comprehensive Psychiatry 45(6):475-482.

Momartin, S., Z. Steel, M. Coello, J. Aroche, D.M. Silove, and R. Brooks

2006 A Comparison of the Mental Health of Refugees with Temporary Versus Permanent Protection Visas. Medical Journal of Australia 185(7):357-361.

Moreira, J.B., and R. Baeninger

2010 Local Integration of Refugees in Brazil. Forced Migration Review 35:48-49.

Nathan, T.

2001 La folie des autres. Traité d'ethnopsychiatrie clinique Paris: Dunod.

Nygaard, M., C. Sonne, and J. Carlsson

2017 Secondary Psychotic Features in Refugees Diagnosed with Post-traumatic Stress Disorder: A Retrospective Cohort Study. BMC Psychiatry 17(1):5.

Oberg, K.

1960 Cultural Shock: Adjustment to New Cultural Environments. Practical Anthropology 4:177-182. 
Papadopoulos, R.K.

2007 Refugees, Trauma and Adversity-Activated Development. European Journal of Psychotherapy and Counselling 9(3):301-312.

Patarra, N.L., and D. Fernandes

2011 Brasil: país de imigração. Revista Internacional em Lingua Portuguesa-Migraçes 3(24):65-96.

Porter, M., and N. Haslam

2005 Predisplacement and Postdisplacement Factors Associated with Mental Health of Refugees and Internally Displaced Persons: A Meta-analysis. JAMA 294(5):602-612.

Reed, R.V., M. Fazel, L. Jones, C. Panter-Brick, and A. Stein

2012 Mental Health of Displaced and Refugee Children Resettled in Low-Income and Middle-Income Countries: Risk and Protective Factors. The Lancet 379(9812):250-265.

Silove, D., I. Sinnerbrink, A. Field, V. Manicavasagar, and Z. Steel

1997 Anxiety, Depression and PTSD in Asylum-Seekers: Associations with Pre-migration Trauma and Post-migration Stressors. British Journal of Psychiatry 170(4):351-357. https://doi.org/10.1192/ bjp.170.4.351.

Silove, D., P. Ventevogel, and S. Rees

2017 The Contemporary Refugee Crisis: An Overview of Mental Health Challenges. World Psychiatry 16(2):130-139.

Silva, D.F., and P.R. de Santana Santana

2012 Transtornos mentais e pobreza no Brasil: uma revisão sistemática. Tempus Actas de Saúde Coletiva 6(4):175-185.

Summerfield, D.

1999 A Critique of Seven Assumptions Behind Psychological Trauma Programmes in War-Affected Areas. Social Science and Medicine 48(10):1449-1462.

Summerfield, D.

2008 How Scientifically Valid is the Knowledge Base of Global Mental Health?. British Medical Journal 336(7651):992.

Syed, M., C. Santos, H.C. Yoo, and L.P. Juang

2018 Invisibility of Racial/Ethnic Minorities in Developmental Science: Implications for Research and Institutional Practices. American Psychologist 73(6):812.

Turrini, G., M. Purgato, F. Ballette, M. Nosè, G. Ostuzzi, and C. Barbui

2017 Common Mental Disorders in Asylum Seekers and Refugees: Umbrella Review of Prevalence and Intervention Studies. International Journal of Mental Health Systems 11(1):51.

UNHCR

2020, June 19 Figures at a Glance. UNHCR. http://www.unhcr.org/figures-at-a-glance.html.

VERBI-Software

2020 MAXQDA 2018 [Computer Software]. Berlin: VERBI Software. https://www.maxqda.com.

Watters, C.

2001 Emerging Paradigms in the Mental Health Care of Refugees. Social Science and Medicine 52(11):1709-1718.

Wolitzky, D.L.

2020 Contemporary Freudian Psychoanalytic Psychotherapy. In Essential Psychotherapies. 4th Edition. S.B. Messer and N.J. Kaslow, eds., pp. 35-70. New York: The Guilford Press.

Yamamoto, O.H.

201250 anos de profissão: responsabilidade social ou projeto ético-político?. Psicologia: ciência e profissão 32(SPE):6-17.

Publisher's Note Springer Nature remains neutral with regard to jurisdictional claims in published maps and institutional affiliations. 